\title{
PERBEDAAN TINGKAT KEPUASAN PASIEN BPJS DAN NON BPJS TERHADAP PELAYANAN PENDAFTARAN DI RSUD TOBELO
}

\author{
Vivia Ozora Bitjoli \\ Odi Pinontoan \\ Andi Buanasari \\ Program Studi Ilmu Keperawatan Fakultas Kedokteran \\ Univeristas Sam Ratulangi \\ Email : viviabitjoli@gmail.com
}

\begin{abstract}
Abstrack:Patient satisfaction level is considered as one of the very important dimension and is one of the main indicators of the standard of a health facility which is due to the influence of health care on the hospital and it is this which makes the measurement of patient satisfaction is an important component.The purpose of this study was to determine the differences between patient satisfaction level on BPJS and Non BPJS users over registration services in Tobelo hospitals. This research method using cross sectional design. The sampling technique used consecutive sampling technique with a total sample of 136 respondents. methods of data collection using questionnaires satisfaction level of service at the place of registration to measure the level of patient satisfaction BPJS and Non BPJS and statistical test using chi square test. The researchresults can be p-value of $0.000(\leq \alpha=$ 0.05), which means there are significant differences. Conclusion there are differences between the level of patient satisfaction level on BPJS and Non BPJS users over registration services in Tobelo hospitals.
\end{abstract}

Keywords: Enrollment Services, BPJS patient and the Non BPJS, Satisfaction

\begin{abstract}
Abstrak : Tingkat kepuasan pasien dianggap sebagai salah satu dimensi yang sangat penting dan merupakan salah satu indikator utama dari standar suatu fasilitas kesehatan yang merupakan akibat pengaruh pelayanan kesehatan atas pihak rumah sakit dan hal inilah yang membuat pengukuran kepuasan pasien menjadi komponen penting. Tujuan penelitian ini adalah untuk mengetahui perbedaan tingkat kepuasan pasien BPJS dan Non BPJS terhadap pelayanan pendaftaran di RSUD Tobelo. Metodepenelitian ini menggunakan desain cross sectional. Teknik pengambilan sampel menggunakan teknik consecutive sampling dengan jumlah sampel sebanyak 136 responden. metode pengumpulan data menggunakan kuesioner tingkat kepuasan pelayanan di tempat pendaftaran untuk mengukur tingkat kepuasan pasien BPJS dan Non BPJS dan uji statistic menggunakan uji chi square. Hasil penelitian di dapat nilai $p$-value sebesar $0,000(\leq \alpha=0,05)$ yang berarti ada perbedaan yang signifikan. Kesimpulan ada perbedaan antara tingkat kepuasan pasien BPJS dan Non BPJS terhadap pelayanan pendaftaran di RSUD Tobelo.
\end{abstract}

Kata kunci : Pelayanan Pendaftaran, pasien BPJS dan Non BPJS, Tingkat Kepuasan 


\section{PENDAHULUAN}

Tingkat kepuasan pasien dianggap sebagai salah satu dimensi yang sangat penting, berkualitas dan merupakan salah satu indikator utama dari standar suatu fasilitas kesehatan yang merupakan akibat pengaruh pelayanan kesehatan atas pihak rumah sakit. Hal inilah yang membuat pengukuran kepuasan pasien menjadi komponen penting (Hayaza, 2013). Badan Penyelenggara Jaminan Sosial (BPJS) merupakan badan hukum publik yang diciptakan guna melaksanakan program jaminan sosial. BPJS ini meliputi BPJS Ketenagakerjaan dan BPJS Kesehatan. BPJS Kesehatan merupakan badan hukum yang diciptakan guna melaksanakan program jaminan kesehatan. Pelaksanaan BPJS Kesehatan mulai beroperasi pada tanggal 1 Januari 2014(Kementerian Kesehatan RI, 2013).

Jumlah peserta BPJS kesehatan secara nasional adalah sebanyak 170.213.981 jiwa/peserta yang terdata pada tahun 2016. Menurut Peraturan BPJS nomor 4 (2014), peserta BPJS kesehatan terbagi dua yang pertama adalah masyarakat tidak mampu yang preminya akan ditanggung oleh pemerintah disebut dengan peserta Penerima Bantuan Iuran (PBI) dan kedua adalah peserta Non PBI terdiri dari Peserta Penerima Upah (PPU), Peserta Bukan Penerima Upah (PBPU) dan Bukan Pekerja yang preminya ditanggung sendiri ataupun kolektif ke BPJS Kesehatan. Awal pelaksanaan program JKN banyak mengalami beberapa kendala antara lain yaitu penduduk masih ada yang belum terdaftar sebagai peserta, distribusi pelayanan kesehatan masih belum merata, kualitas pelayanan kesehatan yang bervariasi, serta pelayanan kesehatan masih belum optimal (Peraturan BPJS Kesehatan No 4, 2014). Permasalahan yang ditemukan oleh Dewan Jaminan Sosial Nasional (DJSN) yaitu masih terdapatnya banyak keluhan darimasyarakat tentang sistem pelayanan yang ada, karena masyarakat tidak mengerti dan paham mengenai metode pelayanan yang sesuai (Saputra, 2015).

Tempat penerimaan pasien rawat jalan merupakan unit pelayanan terdepan bagi setiap rumah sakit. Pelayanan pendaftaran pasien harus mampu mencakup informasi penting mengenai data sosial pasien. Selain itu pemberi pelayanan sebaiknya berpenampilan rapi dan berkomunikasi aktif untuk mendukung pelayanan di rumah sakit. Tata cara melayani pasien dapat dinilai baik bilamana dilaksanakan oleh petugas dengan cepat, sikap yang ramah, sopan, tertip dan penuh tanggung jawab.Untuk menciptakan dan menjaga mutu pelayanan medis yang disesuaikan dengan keinginan masyarakat, maka pihak rumah sakit perlu suatu umpan baik dari masyarakat yaitu tanggapan dan penilaian dari para pasien sehingga dijadikan sebagai suatu bahan evaluasi dan gambaran apakah pelayanan yang diberikan telah memenuhi harapan pasien atau belum.

Pengambilan data awal oleh peneliti berdasarkan data register rumah sakit menunjukkan pada tahun 2017 jumlah kunjungan pasien BPJS pada bulan JanuariDesember sebanyak 13.587 orang, dan pasien umum 9.356 orang dan data jumlah kunjungan di tahun 2018 pada bulan Januari-Agustus sebanyak 12.028 pasien, dengan rata-rata kunjungan perbulan sebanyak 1.665 dan ratarata kunjungan perhari sebanyak 80 pasien. Hasil observasi yang sering di lihat di tempat pelayanan pendaftaran bahwa sering terlihat pasien bertumpuk di tempat pendaftaran, hal ini di sebabkan oleh karena antrian yang panjang dan kurangnya sarana dan prasarana yang tersedia di tempat pendaftaran sehingga kadang pasien BPJS mengeluh kesulitan saat sedang mengantri di tempat pelayanan pendaftaran. Rumah sakit dalam hal inikhususnya di tempat pelayanan pendaftaran dapat mengetahui mutu pelayanan yang di berikan sudah baik atau tidak dari para pasien melalui umpan balik yang di berikan pasien kepada RS khususnya di tempat pendaftaran tersebut. Sehingga dapat menjadi masukan untuk meningkatkan pelayanan di tempat pendaftaran.Berdasarkan dari latar bekang diatas, maka peneliti tertarik untuk meneliti"Perbedaan tingkat kepuasan pasien BPJS dan Non BPJS terhadap pelayanan pendaftaran di RSUD Tobelo.

\section{METODE PENELITIAN}

Penelitian ini termasuk dalam jenis penelitian kuantitatif dengan menggunakan metode penelitian survei analitik untuk menganalisis perbedaan antara 2 variabel yaitu 
variabel independen (pasien BPJS dan Pasien Non BPJS) dan variabel dependen (tingkat kepuasan terhadap pelayanan pendaftaran). Penelitian ini menggunakandesain penelitian cross sectional. Penelitian ini dilaksanakan di RSUD Tobelo pada tanggal 7 Desember 2018. Populasi penelitian ini adalahrata-rata kunjungan pasien perhari sebanyak 80 pasien.Pengambilan sampel menggunakan teknik consecutive sampling dengan rumus slovin maka didapatkan jumlah sampel 68 untuk pasien BPJS dan 68 untuk pasien Non BPJS.Instrument penelitian yang digunakan untuk mengukur variabel tingkat kepuasan terhadap pelayanan pendaftaran menggunakan kuesioner yang pernah digunakan sebelumnya oleh Mustafiah (2015) yang telah diuji validitasnya, kuesioner yang digunakan dalam penelitian ini terdiri dari 11 pertanyaan. 6 pertanyaan untuk pelayanan di tempat pendaftaran, dan 5 pertanyaan untuk pelayanan petugas di tempat pendaftaran dengan pemberian bobot : apabila menjawab "Puas" di beri nilai 3, "Kurang puas" di beri nilai 2 dan apabila menjawab "Tidak Puas" di beri nilai 1.Setelah lembar kuesioner diisi olehresponden, peneliti mengumpulkan kembali lembar kuesioner.

Pengolahan data yang diperoleh dari hasil penelitian ini dianalisis menggunakan uji statistik melalui sistem komputerisasi dengan beberapa tahap yaitu editing, coding, tabulasi data (Notoatmodjo, 2010). Analisa bivariat dalam penelitian ini yaitu untuk mengetahui perbedaan tingkat kepuasan pasien BPJS dan Non BPJS terhadap pelayananan pendaftaran di RSUD Tobelo. Peneliti menggunakan ujiChi Squaredengan tingkat kemaknaan 95\% $(\alpha=0,05)$.

\section{HASIL dan PEMBAHASAN}

\section{Karakteristik Responden}

Tabel 1. Distribusi Responden Berdasarkan Umur

\begin{tabular}{lcccc}
\hline Umur & BPJS & \multicolumn{3}{c}{ Non } \\
& & \multicolumn{3}{c}{ BPJS } \\
\cline { 2 - 5 } & $\mathbf{n}$ & $\mathbf{\%}$ & $\mathbf{n}$ & $\mathbf{\%}$ \\
\hline 17-30 Tahun & 17 & 25 & 17 & 25 \\
31-40 Tahun & 21 & 30,8 & 25 & 36,8 \\
41-50 Tahun & 15 & 22,1 & 15 & 22,1 \\
>50 Tahun & 15 & 22,1 & 11 & 16,1 \\
\hline Total & $\mathbf{6 8}$ & $\mathbf{1 0 0 , 0}$ & $\mathbf{6 8}$ & $\mathbf{1 0 0 , 0}$ \\
\hline Sumber : Data Pring
\end{tabular}

Sumber : Data Primer 2019

Distribusi responden dilihat dari karakteristik berdasarkan umur, Hasil menunjukan bahwa pasien BPJS dan Non BPJS paling banyak berumur 31-40 tahun. Hasil penelitian ini sejalan dengan penelitian Annisa (2016) yang menyatakan bahwa tidak terdapat hubungan yang signifikan antara umur dengan tingkat kepuasan pasien. Tingkat kepuasan pasien umum maupun BPJS dari umur $20-\geq 50$ hampir sama. Pada masa dewasa awal (20-29 tahun) tingkat kepuasan pasien rendah di karenakan pada masa usia tersebut pasien berani mengemukakan pendapat, sedangkan ketika memasuki usia dewasa (3039 tahun) pasien lebih menerima sajapelayanan yang di berikan oleh pihak rumah sakit sehingga tingkat kepuasan meningkat. Pada masa lansia ( $\geq 50$ tahun) tingkat kepuasan pasien kembali menurun di karenakan faktor usia (Annisa, 2016).

Tabel 2. Distribusi Responden Berdasarkan Jenis Kelamin

\begin{tabular}{|c|c|c|c|c|}
\hline \multirow[t]{2}{*}{$\begin{array}{c}\text { Jenis } \\
\text { Kelamin }\end{array}$} & BPJS & \multicolumn{3}{|c|}{$\begin{array}{l}\text { Non } \\
\text { BPJS }\end{array}$} \\
\hline & $\mathbf{n}$ & $\%$ & $\mathbf{n}$ & $\%$ \\
\hline Laki-laki & 19 & 27,9 & 35 & 51,5 \\
\hline Perempuan & 49 & 72,1 & 33 & 48,5 \\
\hline Total & 68 & 100,0 & 68 & 100,0 \\
\hline
\end{tabular}

Berdasarkan Jenis kelamin, diperoleh sebagian besar responden memiliki jenis kelamin perempuan $(72,1 \%)$. Hasil penelitian ini sejalan dengan hasil penelitian oleh Putri (2018) yang menunjukan bahwa sebagian besar pasien BPJS berjenis kelamin 
perempuan merasa puas sedangkan pasien umum sebagian besar pasien laki-laki, artinya tidak terdapat hubungan antara jenis kelamin dengan tingkat kepuasan pasien.

Tabel 3. Distribusi Responden Berdasarkan Pendidikan

\begin{tabular}{ccccc}
\hline Pendidikan & BPJS & \multicolumn{3}{c}{$\begin{array}{c}\text { Non } \\
\text { BPJS }\end{array}$} \\
\cline { 2 - 5 } & $\mathbf{n}$ & \% & n & \% \\
\hline SMA & 54 & 79,4 & 34 & 50 \\
Diploma & 7 & 10,3 & 19 & 27,9 \\
S1 & 7 & 10,3 & 15 & 22,1 \\
\hline Total & $\mathbf{6 8}$ & $\mathbf{1 0 0 , 0}$ & $\mathbf{6 8}$ & $\mathbf{1 0 0 , 0}$ \\
\hline
\end{tabular}

Sumber : Data Primer 2019

Berdasarkan Pendidikan, diperoleh sebagian besar responden berpendidikan SMA $(79,4 \%)$. Hasil penelitian ini sejalan dengan hasil penelitian oleh Mustafiah (2015) yang menunjukkan bahwa sebagianbesar pasien BPJS dan Non BPJS berpendidikan SMA.

Tabel 4. Distribusi Responden Berdasarkan Pekerjaan

\begin{tabular}{|c|c|c|c|c|}
\hline \multirow[t]{2}{*}{ Pekerjaan } & BPJS & \multicolumn{3}{|c|}{$\begin{array}{l}\text { Non } \\
\text { BPJS }\end{array}$} \\
\hline & $\mathbf{n}$ & $\%$ & $\mathbf{n}$ & $\%$ \\
\hline PNS & 9 & 13,3 & 23 & 33,8 \\
\hline $\begin{array}{c}\text { Pegawai } \\
\text { Swasta }\end{array}$ & 7 & 10,3 & 6 & 8,8 \\
\hline Wiraswasta & 11 & 16,1 & 15 & 22,1 \\
\hline IRT & 25 & 36,8 & 20 & 29,4 \\
\hline Lain-lain & 16 & 23,5 & 4 & 5,9 \\
\hline Total & 68 & 100,0 & 68 & 100,0 \\
\hline
\end{tabular}

Sumber : Data Primer 2019

Berdasarkan Pekerjaan, diperoleh sebagian besar responden memiliki pekerjaan IRT (36,8\%). Menurut penelitian Sitompul (2012) Masyarakat yang memiliki status pekerjaan yang lebih baik maka tingkat kepuasannya juga lebih tinggi. Pasien BPJS berstatus bekerja cenderung merasa tidak puas karena sebagian besar dari pasien BPJS tersebut berstatus Non PBI dengan tingkat pekerjaan yang berbeda, yang mana mereka di tuntut untuk membayar premi setiap bulannya sehingga mereka menginginkan pelayanan yang baik. Sedangkan pada pasien umum seseorang yang bekerja memiliki tingkat kepuasan yang tinggi di karenakan mereka memiliki pengetahuan dan pengalaman yang lebih terhadap pelayanan kesehatan di bandingkan dengan orang yang tidak bekerja.

Tabel 5. Distribusi Responden Berdasarkan Penghasilan

\begin{tabular}{ccccc}
\hline Penghasilan & BPJS & \multicolumn{3}{c}{ Non } \\
& & & BPJS \\
\cline { 2 - 5 } & $\mathbf{n}$ & $\mathbf{\%}$ & $\mathbf{n}$ & $\mathbf{\%}$ \\
\hline$<1.000 .000,00$ & 46 & 67,6 & 23 & 33,8 \\
$1.000 .000,00-5.000 .000,00$ & 15 & 22,1 & 31 & 45,6 \\
$>5.000 .000,00$ & 7 & 10,3 & 14 & 20,6 \\
\hline Total & $\mathbf{6 8}$ & $\mathbf{1 0 0 , 0}$ & $\mathbf{6 8}$ & $\mathbf{1 0 0 , 0}$ \\
\hline
\end{tabular}

Sumber : Data Primer 2019

Berdasarkan Penghasilan, diperoleh sebagian besar responden memiliki penghasilan sebanyak $<1.000 .000,00 \quad$ yaitu sebanyak 46 orang $(67,6 \%)$ sedangkan responden terbanyak pasien Non BPJS memiliki penghasilan $1.000 .000,00$ -

$5.000 .000,00$ yaitusebanyak 31 orang $(45,6 \%)$.

\section{Analisa Univairat}

Tabel 6. Tingkat Kepuasan Terhadap Pelayanan Pendaftaran Pasien BPJS

\begin{tabular}{ccc}
\hline & Tingkat Kepuasan & \\
\hline Tidak Puas & Kurang Puas & Puas \\
$\mathbf{\%}$ & $\boldsymbol{\%}$ & $\boldsymbol{\%}$ \\
\hline 3 & 8 & 57 \\
$(33,3)$ & $(29,6)$ & $(57,0)$ \\
2 & 16 & 50 \\
$(28,6)$ & $(38,1)$ & $(57,5)$ \\
18 & 10 & 40 \\
$(75,0)$ & $(25,0)$ & $(55,6)$ \\
2 & 4 & 62 \\
$(33,3)$ & $(17,4)$ & $(57,9)$ \\
2 & 20 & 46 \\
$(16,7)$ & $(29,4)$ & $(68,0)$ \\
3 & 37 & 28 \\
$(37,5)$ & $(54,4)$ & $(41.1)$ \\
\hline
\end{tabular}

Sumber : Data Primer 2019 
Tabel 7. Tingkat Kepuasan Terhadap Pelayanan Pendaftaran Pasien Non BPJS

\begin{tabular}{ccc}
\hline & $\begin{array}{c}\text { Tingkat } \\
\text { Kepuasan }\end{array}$ \\
\hline Tidak Puas & Kurang Puas & Puas \\
$\mathbf{\%}$ & $\mathbf{\%}$ & $\mathbf{\%}$ \\
\hline 6 & 19 & 43 \\
$(66,7)$ & $(70,4)$ & $(43,0)$ \\
5 & 26 & 37 \\
$(71,4)$ & $(61,9)$ & $(42,5)$ \\
6 & 32 & 30 \\
$(25,0)$ & $(47,0)$ & $(44,4)$ \\
4 & 19 & 45 \\
$(66,7)$ & $(82,6)$ & $(42,1)$ \\
10 & 30 & 28 \\
$(83,3)$ & $(46,2)$ & $(47,5)$ \\
5 & 18 & 45 \\
$(62,5)$ & $(39,1)$ & $(54,9)$ \\
\hline
\end{tabular}

Sumber : Data Primer 2019

Hasil analisa pada tabel 6 dan 7 diatas menunjukkan bahwa sebagian besar pasien BPJS merasa puas pada pelayanan di tempat pendaftaran, pelaksanaan antrian, fasilitas di ruang tunggu, kebersihan di ruang tunggu dan tempat duduk yang ada di ruang tunggu tempat pendaftaran, dan sebagian besar pasien BPJS yang kurang puas pada kenyamanan ruang tunggu di tempat pendaftaran. Sedangkan sebagian besar pasien Non BPJS merasa puas pada pelayanan di tempat pendaftaran, pelaksanaan antrian, kebersihan di ruang tunggu dan kenyamanan ruang tunggu di tempat pendaftaran, sedangkan sebagian besar pasien Non BPJS yang merasa kurang puas pada fasilitas di ruang tunggu dan tempat duduk yang ada di ruang tunggu. Kotler (2004) mengatakan pelayanan adalah setiap kegiatan atau manfaat yang ditawarkan oleh suatu pihak kepada pihak lain dan dasarnya tidak berwujud, serta tidak menghasilkan kepemilikan sesuatu. Konsep dasar dari suatu pelayanan (jasa) ataupun kualitas dari suatu produk dapat didefinisikan sebagai pemenuhan yang dapat melebihi dari apa yang diinginkan atau diharapkan pelanggan (konsumen). Penelitian inisejalan dengan penelitian Kuntoro (2017) menunjukan bahwa sebagian besar pasien sudah merasa puas terhadap pelayanan di tempat pendaftaran.

Sistem antrian mencakup pelanggan yang datang dengan laju konstan atau bervariasiuntuk mendapatkan layanan pada suatu fasilitas layanan. Jika pelanggan yang datang dapatmemasuki fasilitas layanan, pelanggan dapat langsung dilayani. Jika pelanggan harusmenunggu dilayani, pelanggan berpartisipasi atau membentuk antrian, dan akan berada dalamantrian hingga pelanggan dapat giliran untuk dilayani. Pelanggan akan dilayani dengan lajulayanan yang konstan atau bervariasi dan akhirnya menginggalkan sistem. Sistem antrianmencakup baik antrian dan fasilitas layanannya (Antono, 2010). Rumah sakit harus mengikuti standar pelayanan minimal tentang waktu tunggu. Standar pelayanan minimal dirawat jalan berdasarkan Kemenkes (2008) adalah kurang atau sama dengan 60 menit. Penelitian ini tidak sejalan dengan penelitian Mustafiah (2015) yang menunjukan bahwa sebagian besar pasien merasa kurang puas terhadap fasilitas di ruang tunggu tempat pendaftaran. Muninjaya (2012) Tuntutan rumah sakit dalam memberikan kualitas pelayanan yang baik dapat meningkatkan derajat kepuasan pasien. Keterlambatan dalam memberikan pelayanan, lamanya prosedur pelayanan, ketersediaan sarana serta ketertiban dan dan kebersihan rumah sakit yang tidak memadai merupakan suatu pengalaman dari ketidakpuasan pasien yang paling sering di kemukakan. Penelitian ini sejalan dengan penelitian Mustafiah (2015) yang menunjukan bahwa sebagian besar pasien merasa puas terhadap kebersihan ruang tunggu di ruang tunggu tempat pendaftaran. Arikuntoro (2009) dalam dimensi tangible atau dimensi kenyaatan karena jasa tidak dapat di amati secara langsung maka pelanggan sering kali berpedoman pada kondisi yang terlihat mengenai jasa dalam melakukan evaluasi. Penelitian ini sejalan dengan penelitian Kuntoro (2017) yang menunjukan bahwa sebagian besar pasien merasa kurang puas terhadap tempat duduk yang ada di ruang tunggu tempat pendaftaran.

Sabarguna (2009) Kepuasan pasien dapat di pengaruhi oleh beberapa faktor penting seperti kenyamanan di ruangan, hubungan pasien dengan staf RS, kompetensi dan biaya. Penelitian ini tidak sejalan dengan penelitian Mustafiah (2015) yang menunjukan bahwa sebagian besar pasien merasa kurang puas 
terhadap kenyamanan ruang tunggu di tempat pendaftaran.

\section{Analisa Bivariat}

Tabel 8. PerbedaanTingkat Kepuasan Pasien BPJS dan Non BPJS Terhadap Pelayanan Pendaftaran

\begin{tabular}{ccccccccccc}
\hline \multirow{2}{*}{$\begin{array}{c}\text { Tingkat } \\
\text { Kepuasan }\end{array}$} & \multicolumn{4}{c}{ Pelayanan Pendaftaran } & \multicolumn{2}{c}{ Total } \\
\cline { 2 - 7 } & \multicolumn{3}{c}{ Puas } & \multicolumn{2}{c}{ Krg Puas } & \multicolumn{2}{c}{ Tdk Puas } & & & \multirow{2}{*}{ Pv } \\
\cline { 2 - 8 } & n & $\%$ & n & $\%$ & n & $\%$ & $\%$ & n & \\
\hline BPJS & 55 & 80,9 & 11 & 16,2 & 2 & 2,9 & 68 & 100 & 0,000 \\
Non BPJS & 18 & 26,5 & 39 & 57,4 & 11 & 16,2 & 68 & 100 & \\
\hline
\end{tabular}

Sumber : Data Primer 2019

Analisa perbedaan tingkat kepuasan pasien BPJS dan Non BPJS terhadap pelayanan pendaftaran di RSUD Tobelo dengan hasil uji menggunakan Chi Square dengan taraf signifikasi $\alpha=5 \%$ diperoleh $\rho$ value $=0,000<0,05$. Hal ini menunjukkan terdapat perbedaan yang signifikan antara tingkat kepuasan pasien BPJS dan Non BPJS terhadap pelayanan pendaftaran di RSUD Tobelo. Hasil penelitian ini sejalan dengan penelitian Siregar (2018) tentang perbedaan tingkat kepuasan pasien BPJS dan Non BPJS terhadap kualitas pelayanan di wilayah puskesmas Dau Malang, hasil penelitianmenunjukkan ada perbedaan yang signifikan antara tingkat kepuasan pasien BPJS dan Non BPJS terhadap kualitas pelayanan di wilayah puskesmas Dau Malang.

Hasil penelitian ini di dukung oleh penelitian Ismawan (2009) bahwa Mengukur tingkat kepuasan pasien terhadap proses pelayanan yang di dapatkan pada pasien BPJS bukan hanya dari sisi medis saja, tetapi juga administrasi di mana sebelum mendapatkan pelayanan medis pasien juga mendapatkan pelayanan dari BPJS terlebih dahulu. Hal ini dapat mempengaruhi kepuasan pasien terhadap rumah sakit, karena kaitannya dengan waktu tunggu saat mendapatkan pelayanan BPJS sebelum mendapatkan pelayanan medis. Proses sistem rujukan berjenjang yang di rasakan setelah adanya BPJS, ini juga mempengaruhi kepuasan pasien terhadap BPJS sendiri.

Sabarguna (2004) Memahami kebutuhan dan keinginan konsumen dalam hal ini pasien adalah hal penting yang mempengaruhi kepuasan pasien. Pasien yang puas merupakan aset yang sangat berharga karena apabila pasien puas mereka akan terus melakukan pemakaian terhadap jasa pilihannya, tetapi jika pasien merasa tidak puas mereka akan memberitahukan dua kali lebih hebat kepada orang lain tentang pengalaman buruknya. Untuk menciptakan kepuasan pasien suatu perusahaan atau rumah sakit harus menciptakan dan mengelola suatu sistem untuk memperoleh pasien yang lebih banyak dan kemampuan untuk mempertahankan pasiennya.

Tindakan atau peran perawat dalam melakukan pelayanan merupakan hal yang sangat mempengaruhi pasien BPJS dan Non BPJS terkait dengan pelayanan yang di terima. Adanya perlakuan yang baik dan penuh perhatian menjadi suatu daya tarik tersendiri dalam pemberian pelayanankepada pasien BPJS dan Non BPJS. Hal ini memberikan kekuatan secara psikologis bagi pasien dan menumbuhkan motivasi untuk memanfaatkan pelayanan yang di berikan, baik itu pelayanan kesehatan maupun pelayanan administrasi.

Ilyas (2002) menyatakan bahwa persepsi yang bersifat abstrak merupakan faktor yang berpengaruh terhadap kepuasan suatu bentuk tertentu dan bukan sesuatu yang konkrit atau aktualnya. Persepsi itu sendiri memiliki suatu aspek yang paling banyak berperan yakni psikologis dari seseorang. Adanya sikap membangun komunikasi yang baik dan juga dukungan situasi lingkungan secara fisik di sekitar pasien atau masyarakat merupakan aspek yang berpengaruh terhadap penilaian pasien itu sendiri. Komunikasi dengan pasien tentang suatu proses pelayanan yang sedang di berikan akan menimbulkan suatu persepsi yang positif dan mendukung dirinya untuk dapat menerima pelayanan yang di berikan. Pelayanan yang cepat tanggap dan di dukung sikap yang ramah serta ketulusan dalam menanggapi persoalan yang di hadapi merupakan hal penunjang dan turut menentukan keberhasilan dalam suatu pelayanan yang di berikan baik pelayanan kesehatan maupun pelayanan administrasi. 


\section{SIMPULAN}

Berdasarkan hasil penelitian, maka kesimpulan yang dapat diambil yaitu :

1. Tingkat kepuasan pasien BPJS terhadap pelayanan di tempat pendaftaran sebagian besar merasa puas pada pelayanan pelaksanaan antrian, fasilitas di ruang tunggu, kebersihan ruang tunggu dan tempat duduk yang ada di tempat pendaftaran.

2. Tingkat kepuasan pasien Non BPJS terhadap pelayanan di tempat pendaftaran sebagian besar merasa kurang puas pada pelayanan fasilitas di ruang tunggu tempat pendaftaran dan tempat duduk yang ada di ruang tunggu tempat pendaftaran.

3. Ada perbedaan antara tingkat kepuasan pasien BPJS dan Non BPJS terhadap pelayanan pendaftaran di RSUD Tobelo.

\section{DAFTAR PUSTAKA}

Annisa, O. Z., Mardiyoko, I., \& Wijayanti, C.A. (2016). Perbedaan Tingkat Kepuasan Pasien BPJS dan Non BPJS Pada Mutu Pelayanan Pendaftaran Rumah Sakit Pusat Angkatan Udara dr. S.Hardjolukito Bantul.

Antono, S. D. (2010). Penerapan Model Simulasi Pada Antrian di Bagian Pengobatan Puskesmas Prambon Kabupaten Jeruk Nganju. Jurnal Penelitian Kesehatan Suara Flores, 1 (4).

Arikuntoro, S. (2009). Prosedur Penelitian Suatu Pendekatan Praktek Revisi V. Jakarta : Rineka Cipta.

Direktur Jenderal Republik Indonesia, (2008) Peraturan Menteri Kesehatan RI No. 129 Tahun 2008 tentang Standar Pelayanan Minimal dirawat Jalan.

Hayaza, Y.T. (2013). Analisis Kepuasan Pasien Terhadap Kualitas Pelayanan Kamar Obat di Puskesmas Surabaya Utara. Jurnal ilmiah Mahasiswa Universitas Surabaya, 2(2), 2-4.

Ilyas, M. A. (2002). Sedimentasi dan dampaknya pada DPS Citarum Hulu.
Jurnal Teknologi Ligkungan, 3(2), 159-164.

Ismawan, N. L. (2009). Analisis Kepuasan dan Hubungannya dengan Loyalitas Pasien Rawat Inap Di Rumah Sakit Dedi Jaya Kabupaten Brebes. Thesis : Universitas Diponegoro Semarang.

Kementerian Kesehatan R.I. (2013). BPJS Kesehatan. Jakarta: Kementerian Kesehatan. 227.

Kotler, P. (2004). Manajemen Pemasaran di Indonesia : Analisis, Perencanaan, Implementasi dan Pengendalian. Salemba Empat. Jakarta.

Kuntoro, W., \& Istiono, W. (2017). Kepuasan Pasien Terhadap Kualitas Pelayanan di Tempat Pendaftaran Pasien Rawat Jalan Puskesmas Kretek Bantul Yogyakarta. Jurnal Kesehatan Vokasional, 2 (1).

Muninjaya, G. (2012). Manajemen Mutu Kesehatan. EGC : Jakarta.

Mustafiah. (2015). Kepuasan Pasien Terhadap Pelayanan Di Tempat Pendaftaran Rumah Sakit Permata Bunda Purwodadi.

Notoatmodjo, S. (2010). Metodologi Penelitian Kesehatan. Jakarta : Rineka Cipta.

Peraturan BPJS Nomor 4 tahun (2014) tentang tata cara pendaftaran dan pembayaran peserta perorangan badan penyelenggara jaminan sosial kesehatan.

Putri, N. R. (2018). Pengaruh Pelayanan SDM Terhadap Tingkat Kepuasan Pasien di Pelayanan Rawat Jalan RS X Jambi (Analisis Perbandingan Pasien Umum dan BPJS).

Sabarguna. (2004). Quality Assurance Pelayanan Rumah Sakit. Konsorsium Rumah Sakit Islam Jateng - DIY : Yogyakarta. 
e-journal Keperawatan (e-Kp) Volume 7 Nomor 1, Mei 2019

Sabarguna, B. S. (2009). Pemasaran Pelayanan Rumah Sakit. Sagung Seto, Jakarta.

Saputra, M., Marlinae, L., Rahman, F., \& Rosadi, D. (2015). Program Jaminan Kesehatan Nasional dari aspek Sumber Daya Manusia Pelaksana Pelayanan Kesehatan. Jurnal Kesehatan Masyarakat, 11 (1), 32-42.

Siregar, N., Hariyanto, T., \& Ahmad, S. Z. (2018). PERBEDAAN TINGKAT KEPUASAN PASIEN BPJS DAN NON BPJS TERHADAP KUALITAS PELAYANAN DI WILAYAH PUSKESMAS DAU MALANG. Nursing News : Jurnal Ilmiah Mahasiswa Keperawatan, 3 (2).

Sitompul, J. (2012). Faktor-faktor Yang Berhubungan Dengan Kepuasan Peserta Askes Sosial Terhadap Pelayanan Askes Center Di Rs. Depati Hamzah Pangkalpinang. Universitas Indonesia, Jakarta. 